\title{
Osteogenic Differentiation Potential of Bone Marrow Stem Cells Compared To Umbilical Cord Blood Stem Cells
}

\author{
Nagwan A. Sabek ${ }^{*}$, Ahmed T. El Serfi, Shymaa A Maher \\ Department of Medical Biochemistry, Faculty of Medicine, Suez Canal University, Egypt
}

\begin{abstract}
Background: Runx2 and Osterix are the key transcription factors initiating and regulating the early osteogenesis and late mineralization of bone. Regenerative medicine is an evolving field of medical researches; this field holds the promise of regenerating damaged tissues and organs in the body by replacing damaged tissue and by stimulating the body's own repair mechanisms to heal previously irreparable tissues or organs. Aim: to investigate the osteogenic differentiation potential of mesenchymal stem cells isolated from human bone marrow (BM) and umbilical cord blood (UCB). Methods: Mononuclear cells isolated from human UCB and BM were differentiated into spindle shaped fibrous mesenchymal stem cells (MSCs) in Dulbecco modified Eagle's medium (DMEM) with $10 \%$ fetal bovine serum. These progenitor cells were further examined for their ability to differentiate into osteoblasts by culture in osteogenic differentiation media containing; dexamethazone and ascorbate-2phosphate and by the detection set of osteogenic genes expression including; Runx-2 and Osterix, and the markers of osteogenic genes differentiation: Collagen1 and alkaline phosphatase (ALP). Results: Runx-2 gene was significantly expressed about 7 fold in BM derived cells treated for 24 hours compared to control sample (which was not treated by osteogenic differentiation media) (7.2 \pm 1.1 vs. $1.0 \pm 0.1, p=0.02)$. In addition, there was significantly expression about 3 to 4 folds in UCB compared to control sample $(3.4 \pm 0.4$ vs. $0.6 \pm 0.1, p=0.04)$. We also found that Osterix gene expression was significantly increased in BM MSCs treated samples for 24 hours about 3 folds relative to control $(3.2 \pm 0.4$ vs. $1.0 \pm 0.14, p=0.02)$ and increased in UCBMSCs samples treated for 24-72 hours about 2-4 folds respectively compared to control sample (2.1 \pm 0.5 vs. $0.7 \pm 0.09, p=0.07$ ). Conclusions: we conclude that i) UCBMSCs are capable of mineralization when cultured in osteogenic medium and would be a better cell source for treatment of osteogenic repair. ii) A significant change in osteogenic genes expression was found between both sources of mesenchymal stem cells indicating that BM MSCs have a higher osteogenic differentiation potential than UCB MSCs although UCB MSCs had proven to be an alternative source for mesenchymal stem cells and these cells are successfully differentiated into osteoblasts.
\end{abstract}

Key words: cord blood cells, mesenchymal stem cells, osteogenic differentiation, Osterix, Runx2

\section{Introduction}

Human mesenchymal stem cells (hMSCs) are multipotent stem cells, which naturally give rise to connective tissue such as bone, cartilage, making bone regeneration one of the most investigated therapeutic areas for
hMSCs today ${ }^{(1)}$ Osteogenic differentiation of Human mesenchymal stem cells hMSCs, from various sources will make the bone regeneration a possible task ${ }^{(2,3)}$. Bone marrow stromal cells (BMSCs), which can differentiate into osteoblasts (OBs) by appropriate induction, have become one of the 
most important cells for bone tissue engineering. Due to the multipotent differentiation capability of BMSCs, it is valuable to develop the technique of controlling, maintaining and promoting the osteogenesis of BMSCs $^{(4,5)}$. Runt-related transcription factor-2 (Runx-2) is essential for osteoblast differentiation and skeletal development during the early stages of embryogenesis. ${ }^{(6)}$ The role of Runx-2 on regulating osteogenic differentiation is revealed by inhibiting the formation of mineralized nodules with Runx-2 antisense oligonucleotides, while forced expression of Runx2 in non-osseous mesenchymal cells induces expression of osteoblast phenol-typic genes $^{(7,8)}$. The role of Runx-2 on regulating bone phenotypic genes was demonstrated that Runx-2 can up-regulate the expression of Osteocalcin, but also interacts with other genes, such as Osterix (Osx) $)^{(9,10)}$. Subsequent studies revealed that Runx-2 can also down-regulate various bone-related genes, including the collagen type I ( $\mathrm{Col} \mathrm{I}$ ) and bone sialo-protein $^{(11)}$. Col I is the major organic component of bone extracellular matrix produced by osteoblasts ${ }^{(12)}$. Runx-2 and Osterix are transcription factors that are crucial for osteoblast differentiation. Runx2 is the master transcription factor involved in the osteogenesis process. This transcription factor directs multipotent and pluripotent mesenchymal cells to the osteoblastic lineage, and inhibits them from differentiating into the adipocytic and chondrocytic lineages ${ }^{(10)}$. Osx is a novel zinc fingercontaining transcription factor that is essential for osteoblast differentiation and bone formation ${ }^{(13)}$. In Osx-null mutant mice, neither endochondral nor intramembranous bone formation occurs, and osteoblast differentiation is arrested ${ }^{(12)}$. After differentiating to pre-osteoblasts, Osterix, and Runx-2 direct them to immature osteoblasts, which produce bone matrix proteins, during osteoblast differentiation,
Runx-2 up regulates the expression of bone matrix protein genes including type 1 collagen $^{(13)}$. Markers of osteogenic differentiation include collagen 1 and alkaline phosphatase (ALP), Collagen1 is the most abundant protein in animals, makes up about (90-95\%) of the organic content of bone; thus collagen is the main constituent of the bone matrix ${ }^{(14)}$. Umbilical cord blood (UCB) contains a population of mesenchymal stem cells (MSCC), these cells have similar cellular, morphological and differentiation properties to bone-marrow MSCc but at the same time, show advantages over bone-marrow MSCc that its differentiation potential and its number decrease with age ${ }^{(15,16)}$. Research groups have shown that these cells (UCB) can be differentiated into hepatocytes, osteoblasts, adipocytes, chondrocytes as well as neural cells ${ }^{(17,18)}$. The abundance, accessibility and differentiation potential of UCB stem cell populations made it a promising source of stem cells for research and clinical applications including transplantations ${ }^{(19,20)}$. Umbilical cord blood cells are easier to obtain, cause no harm to the donor while bone marrow involves invasive technique to obtain the cells. Therefore, the umbilical cord blood stem cells can be viewed as a potential source of stem cells for clinical and non-clinical research applications. In this present work, we investigated the osteogenic differentiation potential of MSCs isolated from umbilical cord blood compared to those isolated from bone marrow by determined the osteogenic gene expression including; Runx-2, Osterix, Collagen 1 and ALP as the markers of osteogenic genes differentiation.

\section{Material and Methods}

MSCs were isolated from BM and UCB and examined for their ability to differentiate into osteoblasts by culture into osteogenic differentiation media. 
1- Isolation of MSCs from UCB

Cord blood was freshly collected from fullterm babies of healthy women from the obstetric Emergency room of the Suez Canal University Hospital. Cord blood was diluted 1:1 in Phosphate Buffer Saline (PBS). $35 \mathrm{~mL}$ of the diluted blood was carefully layered over $15 \mathrm{~mL}$ Ficoll ${ }^{*}$, and centrifuged at $500 \times \mathrm{g}$ for $15 \mathrm{~min}$ in swinging bucket centrifuge. Once we obtained the density gradient separation of cord blood contents (Figure 1). The mononuclear cell (MNCs) fraction was carefully aspirated in to sterile tube. MNCs fraction was washed once with PBS and cultured in a-MEM with low glucose $(1000 \mathrm{mg} / \mathrm{L})^{*}$ containing $10 \%$ Fetal Bovine serum $(\mathrm{FBS})^{*}, 1 \%$ L-glutamine ${ }^{*}$, and $1 \%$ penicillin/streptomycin. The culture plates were incubated in a humidified $\mathrm{CO}_{2}$ Incubator with $5 \% \mathrm{CO}_{2}$ at $37 \mathrm{C}^{\circ(21)}$

2-Isolation and Cultivation of MSCs from BM Bone marrow stromal cells were isolated from the bone marrow aspirate obtained from three donors (43-78 years old) undergoing total hip replacement after taking patient consent (faculty of medicine, Suez Canal University Hospital). Briefly, adherent cells derived from marrow stroma were maintained as monolayer cultures and expanded in basal medium containing Dulbecco's modified Eagle's medium (DMEM), 10\% FBS, 100 units/ml penicillin and 100 $\mu \mathrm{g} / \mathrm{ml}$ streptomycin. Cells at passage 3-4 were cultured in 25 -flask at initial seeding cell densities of 5,000 cells $/ \mathrm{cm}^{2(22)}$.

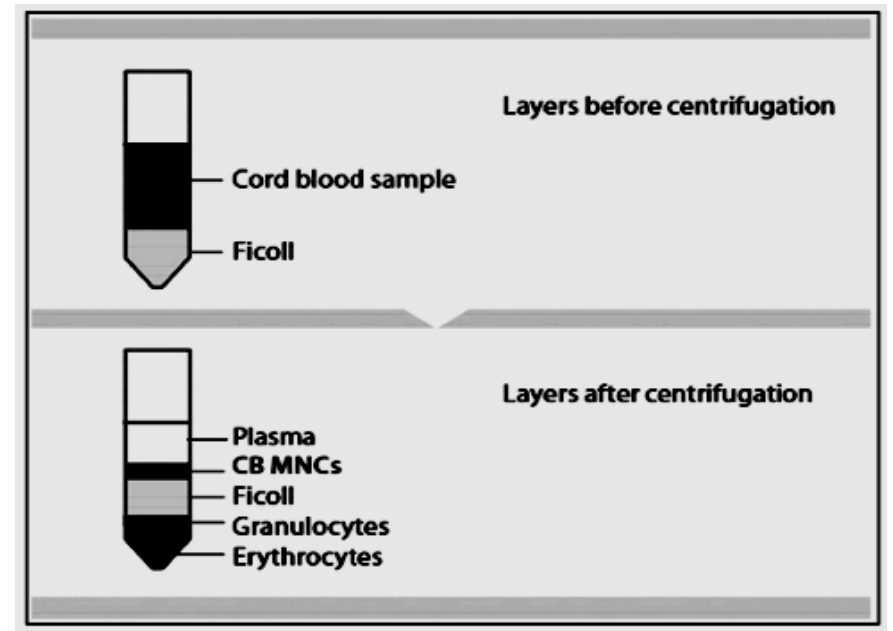

Figure 1: Schematic diagram of density gradient centrifugation

\section{3- Osteogenic Differentiation}

For osteogenic differentiation, human mesenchymal stem cells (hMSCs) were initially cultured in DMEM $\left(3.5 \times 10^{3}\right.$ cells $\left./ \mathrm{cm}^{2}\right)$. After 24 hours, the media is changed with osteogenic differentiation media which includes, the basal conditions with addition 2 $\mu \mathrm{l}$ ascorbate-2-phosphate*, and $11 \mu \mathrm{l}$ dexamethasone* for each $1 \mathrm{ml}$ of growth media. Half of the conditioned medium was replaced with fresh medium every 2-3 days. When cells from both sources reach $50 \%$ confluence, osteogenic media was added to induce osteogensis. We used DMEM supplemented with 10\% FBS, I-glutamine, Penicillin/Streptomycin and dexamthasone as control medium ${ }^{(23)}$

(*Sigma Aldrich Ltd , St. Louis, Mo, USA).

\section{Microscopic Observations}

For growth and morphology of hMSCs from cord blood and bone marrow, we monitor the culture flask at regular intervals by phase contrast microscope (Leica, 
Cambridge, England), and pictures were recorded using digital camera.

Total RNA Isolation and RT-PCR Reaction

RNA was extracted from induced BM-MSCs after 24 hours, from UCB-MSCs after 24-72 hours, and from untreated control samples (when cells reached 50\% confluence in both groups). Then RNA will be reverse transcribed to cDNA by using Quanti Tect Reverse Transcription Kit (Cat. No. 205311). The mRNA expression of Runx2 (a critical transcriptional factor that regulates skeletogenesis) ${ }^{(19)}$, osterix (Osx; an essential transcription factor that initiates mineralization) ${ }^{(12)}$, type I collagen (Col I; a major organic component that exists in bone extracellular matrix) alkaline phosphatase ${ }^{(20)}$, and glyceraldehyde 3-phosphate dehydrogenase (GAPDH; as an internal control for RNA loading) in control were determined at each time point by reverse transcriptase-polymerase chain reaction (RT-PCR) assay. Total RNA was extracted and collected by using Qiagen RNeasy Mini Kit (Cat. No. 74104), and the first-strand cDNA was synthesized by using the Super Script First-Strand Synthesis System followed by the amplification of cDNA product using the real-time polymerase chain reaction ( $P C R$ ) technique ( $A B I$ 7000). The sense and antisense sequences of the primers used for detection of gene expression are listed in Table 1. The reaction was performed under the following conditions: incubation at $94^{\circ} \mathrm{C}$ for $2 \mathrm{~min}$; denaturation at $94^{\circ} \mathrm{C}$ for $45 \mathrm{~S}$, annealing at $51^{\circ} \mathrm{C}$ (Runx2), $58^{\circ} \mathrm{C}$ (Osx), $60^{\circ} \mathrm{C}$ (ALP and $\mathrm{Col} \mathrm{I}$ ), and $52^{\circ} \mathrm{C}$ $(\mathrm{GAPDH})$ for $30 \mathrm{~s}$, and polymerization at $72^{\circ} \mathrm{C}$ for $60 \mathrm{~s}$ for $30-35$ cycles; followed by a final extension at $72^{\circ} \mathrm{C}$ for $5 \mathrm{~min}$.

Table 1: Primers Sequences for RT-PCR Analysis

\begin{tabular}{|l|l|}
\hline Primer & Sequence \\
\hline $\begin{array}{l}\text { GAPDH } \\
\text { (house keeping gene) }\end{array}$ & $\begin{array}{l}\text { Forward: 5' CCAGGTGGTCTCCTCTCACTTC 3' } \\
\text { Reverse: 5' TCATACCAGGAAATGAGCTTGACA 3' }\end{array}$ \\
\hline Runx-2 & $\begin{array}{l}\text { Forward: 5' TCTTCACAAATCCTCCCC 3' } \\
\text { Reverse: 5'TGGATTAAAAGGACTTGGTG 3' }\end{array}$ \\
\hline Osterix & $\begin{array}{l}\text { Forward:5'TAGTGGTTTGGGGTTTGTTACCGC 3' } \\
\text { Reverse:5'AACCAACACTCTTATTCCCTAAGT 3' }\end{array}$ \\
\hline ALP & $\begin{array}{l}\text { Forward: 5' AAGGCTTCTTCTTGCTGGTC 3' } \\
\text { Reverse: 5' GCCTTACCCTCATGATGTCC 3' }\end{array}$ \\
\hline Col1 & $\begin{array}{l}\text { Forward:5' GCCAAGACGAAGACATCCCA 3' } \\
\text { Reverse: 5' CCACACGTCTCGGTCATGG 3' }\end{array}$ \\
\hline
\end{tabular}

Relative expression of genes Runx2, Osterix, ALP and Collagen type 1 were determined using the real-time polymerase chain reaction technique ( $A B I$ 7000), Master mix was prepared by using QuantiTect SYBR Green PCR Kit (Cat. No. 204141). The expression level of each gene will be corrected to a house-keeping gene. Master Mix was prepared using the SYBR Green hot-start master mix. Program of real-time cycler was according to table (2). After the $\mathrm{PCR}$ program end the $\mathrm{CT}$ of the samples were taken from the PCR device, each gene and housekeeping gene for each sample were taken to determine fold change of gene expression by the following equation: $\Delta C T=C T$ target $-\mathrm{CT}$ reference (housekeeping gene). $\Delta \Delta C T=\Delta C T$ test sample $-\Delta C T$ calibrator (control) sample. $\mathrm{RQ}=$ Gene expression $=2{ }^{\Delta \Delta \mathrm{ct}}$. The quantification was performed using $2^{-\Delta \Delta C t}$ methods ${ }^{(24)}$. This method depends on normalizing the cycle number $(\mathrm{Ct})$ of the gene of interest to that of a housekeeping gene in the same sam- 
ple at certain cut-off level to determine $\Delta \mathrm{Ct}$ value. Then one of the samples was set as a reference and all samples were subtracted from this particular sample calculated as $2^{-}$ $\Delta \Delta C \mathrm{Ct}$ and represented as mean $\pm S D$, while the reference result was one.

Table 2: Real-time cycler program

\begin{tabular}{|l|c|c|}
\hline Step & Time & Temperature \\
\hline PCR initial heat activation & $15 \mathrm{~s}$ & $95^{\circ} \mathrm{C}$ \\
\hline denaturation & $15 \mathrm{~s}$ & $95^{\circ} \mathrm{C}$ \\
\hline annealing & $30 \mathrm{~s}$ & $50^{\circ} \mathrm{C}$ \\
\hline extension & $40 \mathrm{~s}$ & $72^{\circ} \mathrm{C}$ \\
\hline Number of cycles & 45 & \\
\hline
\end{tabular}

\section{Statistical Analysis}

Statistical analysis was done using Statistical Package for Social Science software (SPSS 14.0, Chicago, IL). All assays were repeated, with a minimum of $n=3$ per group. Data are expressed as mean and SD values. Statistical significance was determined using one-way ANOVA to compare means between groups, with a $p$ value of less than 0.05 being considered statistical significant.

\section{Results}

The present study compared the osteogenic differentiation potential between mesenchymal stem cells isolated from bone marrow and umbilical cord blood when treated with dexamethasone and ascorbate 2 phosphates for 24-72 hours, and for detection the up-regulated osteogenic genes expression of Runx-2, Osterix, ALP and Col1.

\section{Isolation of Mesenchymal Stem Cells}

After an incubation period of two to three days, we were successful in isolating mesenchymal stem cells (MSCs) from the mononuclear cells (MNCs) of bone marrow and cord blood. The adherent cell population with spindle shape, fibroblast like morphology confirms them as mesenchymal progenitors (Figures 3, 4). In our study, MNCs which was isolated from cord blood (14.1 $\pm 9.14 \times 10^{7}$ cells), and bone marrow $\left(19.3 \pm 3.37 \times 10^{7}\right.$ cells) were cultured immediately in $\mathrm{T}-25$ tissue culture sterile plastic flasks. Adherent cells were detected in all samples 24 hours after their culture with increasing in number with time. The appearance of spindle-shaped MSC-like adherent cells was noticed $(4.7 \pm 1.6)$ days for bone marrow and $(6.7 \pm 1.6)$ days for cord blood after onset of culture.

1- Runx-2 and Osterix genes expression

Our results showed that there was a statistically difference in Runx-2 gene expression in BM-MSCs compared to UCB-MSCS (treated, with osteogenic factors for 24 and $72 \mathrm{hrs}$ ), and they were increased relative to control (Figure 5 , and Table 3 ). Figure 6 , and table 4 showed the fold changes of Osterix gene expression in different groups of samples. Osterix gene expression increased in BM-MSCs (treated samples for $24 \mathrm{hrs}$ ) about 3 folds relative to the control, and increased in UCB-MSCs samples (treated for 24-72 hrs) about 2-4 folds compared to control sample. It was double in UCB-MSCs (treated for $72 \mathrm{hrs}$ ) compared to those treated for $24 \mathrm{hrs}$. 


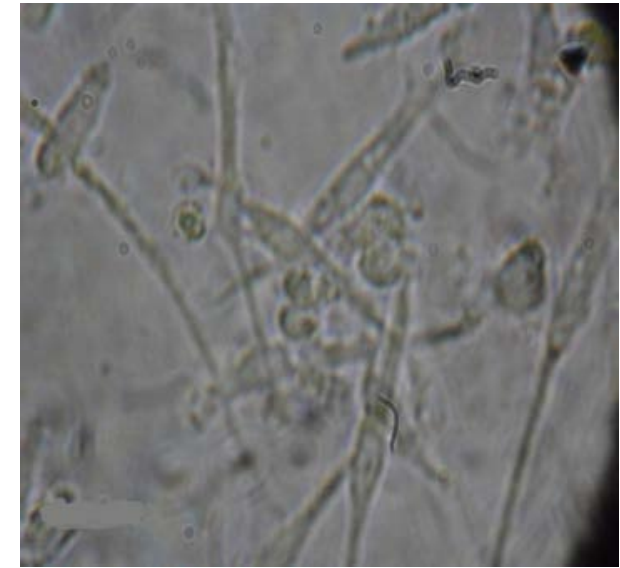

Figure 3: UCB-derived adherent cells, with predominance of MSC-like spindle shaped cells after 4 days of culture (x40).

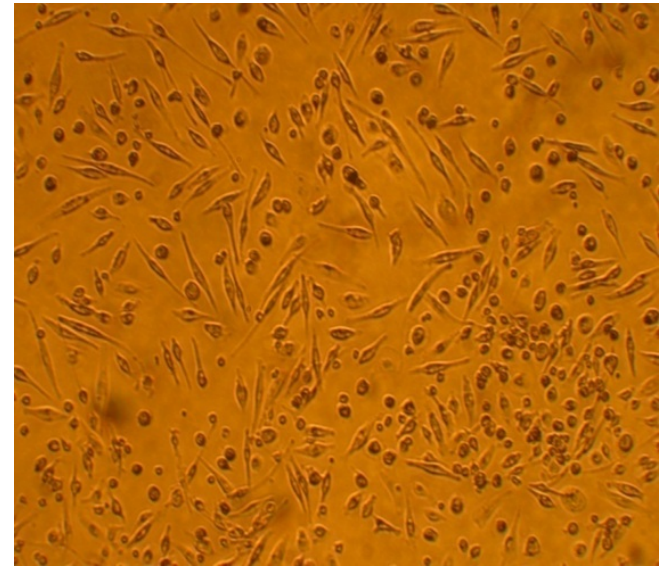

Figure 4: The predominance of spindle shape BM MSCs after 4 days of culture.

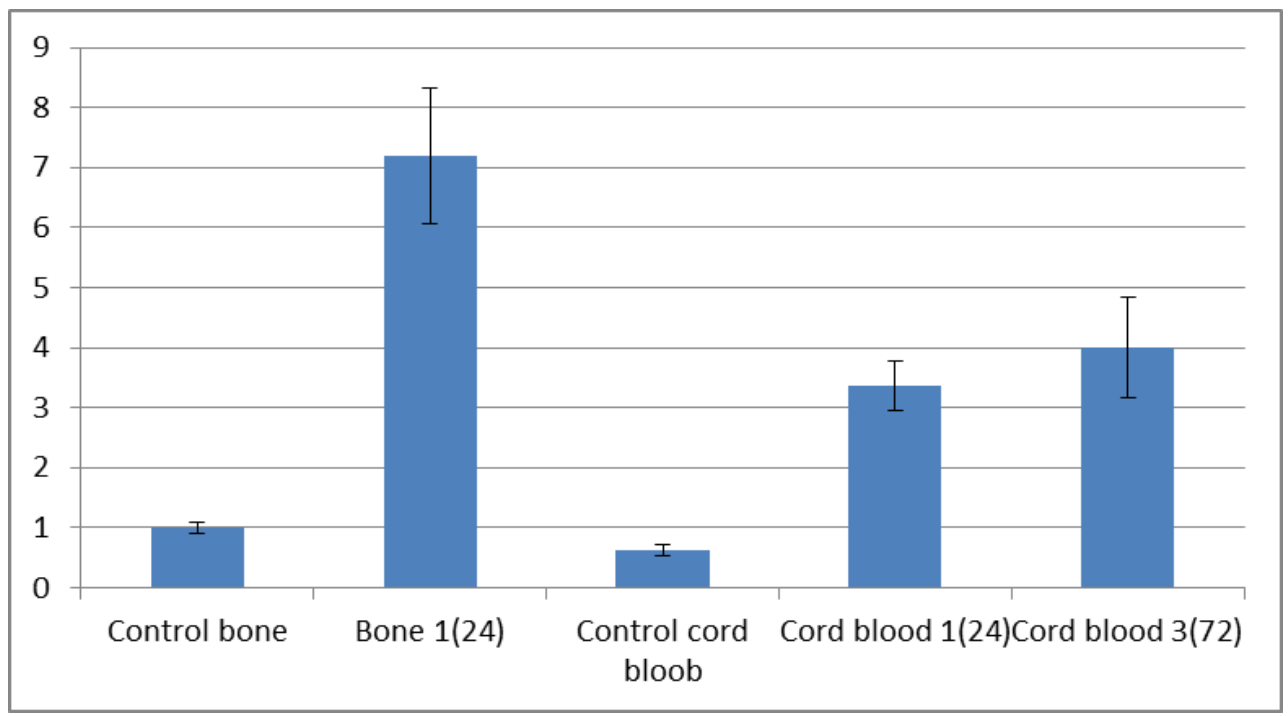

Figure 5: Fold changes in gene expression: Runx-2 gene expressions in BM control and after treated samples for 24 hours and cord blood control and after treated samples for $24-72$ hour.

Table 3: The mean $\Delta c t$ of Runx- 2 gene expression in BM- MSCs compared to CB- MSCS

\begin{tabular}{|l|ccc|}
\hline Runx-2 & BM- MSCs & UCB- MSCs & $p$-value \\
\hline Control & $1.0 \pm 0.1$ & $0.6 \pm 0.1$ & $0.02^{*}$ \\
MSCs Treated 24 hrs & $7.2 \pm 1.1$ & $3.4 \pm 0.4$ & $0.04^{*}$ \\
BM treated 24 hrs vs. CB treated 72 hrs & $7.2 \pm 1.1$ & $4.0 \pm 0.9$ & $0.04^{*}$ \\
\hline
\end{tabular}

Data are presented as Mean $\Delta \mathrm{ct} \pm \mathrm{SD}$; *=statistically significant at $\mathrm{p}<0.05$; $\mathrm{BM}-\mathrm{MSCs}=$ Bone marrowmesenchymal stem cell; UCB- MSCs = Umbilical cord blood-mesenchymal stem cells.

There was a statistically significant difference in ALP gene expression in BM-MSCS samples treated for 24 hours compared to BM-MSCs control, $p=0.01$ (Table 5). Our results also showed that ALP gene expression was undetected in UCB-MSCs in treat- ed and untreated samples. Our result showed that Collagen 1 gene expression was not detected in either BM-MSCs control or treated groups. In addition, it was not detected in UCB-MSCs control or treated groups. 


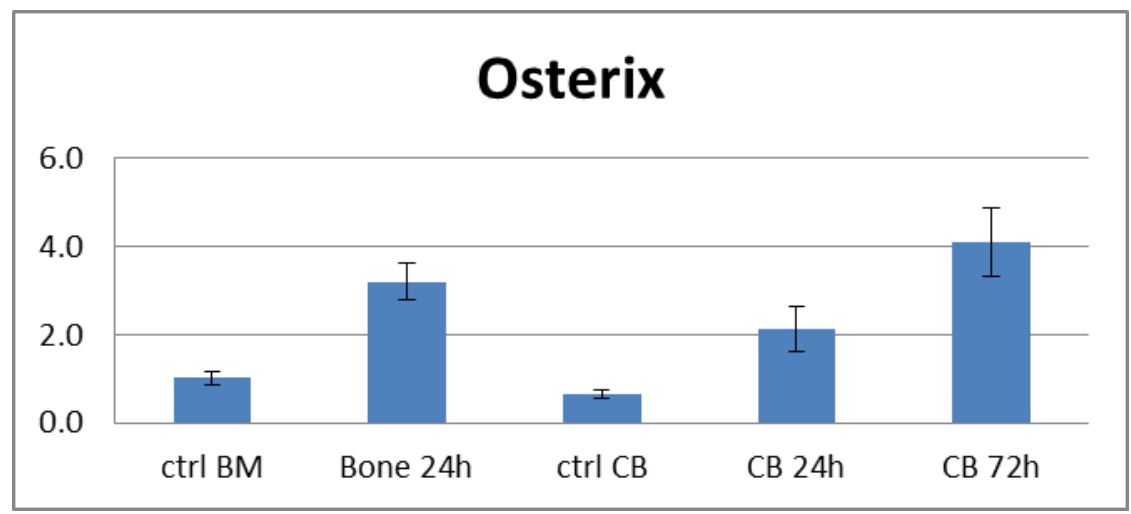

Figure 6: Fold changes in osterix gene expression in bone marrow control and after 24 hour treated samples and cord blood control and cord blood after 24-72 hours treated samples.

Table 4: The mean $\Delta \mathrm{ct}$ of osterix gene expression in BM- MSCs compared to CB- MSCs

\begin{tabular}{|l|ccc|}
\hline osterix & BM- MSCs & UCB- MSCs & p-value \\
\hline Control & $1.0 \pm 0.14$ & $0.7 \pm 0.09$ & $0.02^{*}$ \\
Treated 24 hrs & $3.2 \pm 0.43$ & $2.1 \pm 0.51$ & $0.07^{*}$ \\
UCB treated 72 hrs vs. BM treated 24 hrs & $3.2 \pm 0.43$ & $4.1 \pm 0.78$ & 0.2 \\
\hline
\end{tabular}

Data are presented as mean $\Delta \mathrm{ct} \pm \mathrm{SD} ;{ }^{*}=$ statistically significant at $\mathrm{p}<0.05$; BM- $\mathrm{MSC}=$ Bone marrowmesenchymal stem cells; UCB- MSCs = Umbilical cord blood-mesenchymal stem cells.

Table5: The mean $\triangle \mathrm{ct}$ ALP gene expression in BM- MSCs control and treated for $24 \mathrm{hrs}$

\begin{tabular}{|c|c|c|c|}
\hline ALP (gene expression) & BM control & BM treated 24 hours & p-value \\
\hline Mean $\Delta \mathrm{ct} \pm$ SD & $0.93 \pm 0.12$ & $3.69 \pm 0.29$ & $0.01^{*}$ \\
\hline
\end{tabular}

BM- MSCs= Bone marrow- mesenchymal stem cells; ALP= alkaline phosphatase; *=statistically significant at $p<0.05$.

\section{Discussion}

The aim of this work was to compare MSCs isolated from $B M$ to $U C B$ regarding their osteogenic differentiation potential by comparing the expression of the osteogenic master genes Runx- 2 and Osterix (transcription factors responsible for the development of bones in embryos as well as fracture healing in postnatal life) and ALP, which is an important enzyme in the formation of bone matrix and collagen I, the most abundant protein in the osteogenic matrix. We report that hMSCs from umbilical cord blood are capable of undergoing osteogenic differentiation, by detection the up-regulated osteogenic genes expression of Runx-2 and Osterix. On the other hand; hMSCs from umbilical cord blood can be regarded as osteogenic progenitor/precursor cell population that can be acquired on regular basis from caesarean section ${ }^{(12)}$. It has proven that, hMSCs from the umbilical cord blood have the skills to proliferate extensively and maintain its osteogenic differentiation in vitro $^{(13)}$. In our study, results obtained from the gene expression of Runx-2 and Osterix confirmed that osteogenic differentiation of the hMSCs layers during their cultured in osteogenic differentiation media. This osteogenic potential of cord blood derived progenitors may be useful for autologous transplantations in near future. 
MSCs play a vital role in cell regeneration and the repair of damaged tissues in human growth. The ease of culturing and expanding MSCs ex vivo has spurred numerous therapeutic applications and clinical trials ${ }^{(25)}$. MSCs can be isolated from bone marrow, umbilical cord blood, adipose tissue, and placenta. Although bone marrow (BM) has been regarded as a major source of MSCs, umbilical cord blood has been considered as an alternative source for isolation of $\mathrm{MSC}^{(26)}$. The efficiency of isolation of MSCs from cord blood was reported in some literature to be low. Rebelatto et al $(2008)^{(27)}$ have success rate of $30 \%(n=3 / 10)$ which may be due to their small sample size. However, others reported higher rates; Bieback et al., $(2004)^{(28)}$ isolated MSC-like cells from HUCB units with efficiency greater than $60 \%(n=37 / 59)$, while Kern et al., (2006) had a success rate of $63 \%(n=38 / 59)^{(29)}$. In our study, the isolation efficacy of MSCs from cord blood was comparable to previous reports ${ }^{(29)}$. The success rate of MSC-like cells isolation from HUCB is still low in comparison to both. The explanation of this could be attributed to the fact that UCB-MSCs are circulating in the prenatal blood, its viability and count can be affected by any blood events, such as minute blood clots with subsequent trapping of some MSCs. In our study both types of cells exhibited typical MSCs characteristics; adherent to plastic surface of the flask and fibroblastoid morphology with no morphologic differences between cells from both sources, as was reported by Rebelatto et al. in $2008^{(27)}$. Regarding gene expression, we found that Runx-2 and Osterix genes were expressed in bone marrow mesenchymal cell samples and in cord blood samples, there was statistically significant expression of Runx-2 gene and osterix gene in bone marrow mesenchymal stem cell treated samples in comparison to control and that bone marrow cell ex- pressed higher levels of Runx-2 and Osterix in comparison to cord blood derived cells without any prior induction. Thus, bone marrow mesenchymal stem cells show higher osteogenic potential than that of cord blood derived mesenchymal stem cells. These findings may be explained as the stem cell niche where MSCs derived from bone marrow are already present in osteogenic environment in bone marrow, including the physical effects, paracrine secretions and extracellular mediators. This finding is in agreement with Shafiee et al., $2011^{(30)}$ who found that Runx-2 gene was significantly expressed in higher level in BM-MSCs during its induction compared to cord blood, this indicate that bone marrow showed higher capacity for osteogenic differentiation than cord blood. Stan et al., $(2003)^{(31)}$ found that bone marrow mesenchymal cells express Runx-2 and Osterix genes in both induced and non-induced culture. Also, Peng et al., (2008) ${ }^{(32)}$ found that Runx-2 gene expression was peaked at 3-7 days in induced BM-MSCs, well ahead of UCB-MSCs concluded that BM-MSCs exhibited superior capacity to osteogenic differentiation than CB- MSCs. Maeno et al., 2011 found that Runx-2 is sufficient to direct mesenchymal cells to osteoblast and that Runx expression is essential for skeletal development. In our study Osterix gene expression was significantly higher in UCBMSCs treated for 72 hours than BM-MSCs treated for 24 hours. Komori, 2006 found that Runx and Osterix directed mesenchymal cells to immature osteoblast which blocks their potential to differentiate into chondrocytes. Kanczler and Oreffo, $2008^{(33)}$ used osterix as a marker of osteogensis for bone marrow mesenchymal cells and found that inhibition of the expression of Osterix can control rate of differentiation by maintaining cell in a pre-osteoblastic stage. Regarding downstream genes ALP and COL1, we found that 
ALP was expressed in bone marrow mesenchymal cell samples but was not expressed in cord blood cell samples and this expression significantly was increased in BM treated cells for 24 hours relative to control, its expression was about 3.7 fold relative to control, while collagen type 1 gene expression was not detected in mesenchymal stem cells derived from both sources. These results may be explained as bone marrow was the tissue of origin and may be more time was needed for induction of UCB-MSCs. Our result was consistent with shafiee et al. (2011) ${ }^{(30)}$ who found that ALP activity reach peak in cord blood before bone marrow at day 7 and day 14 respectively but that BM-MSCs have the highest ALP activity during induction.

\section{Conclusion}

In conclusion, our result showed that there was significant change in osteogenic genes expression between mesenchymal stem cells from both sources indicating that bone marrow mesenchymal cells have a higher osteogenic differentiation potential than cord blood cells. But umbilical cord blood had proven to be an alternative source for mesenchymal stem cells and these cells are successfully differentiated into osteoblasts.

\section{Limitation of the study}

Number of samples subjected to statistical analysis was 3 for bone marrow and umbilical cord blood. One of the limitation was obtaining bone marrow samples as it was obtained from patient undergoing total hip replacement operation another which was more important was the risk of infection so it take us about 12 bone marrow and 35 cord blood samples to get 3 samples free of infection with viable cells to complete the study.

\section{References}

1. GeorgeJ, Kuboki Y, Miyata T. Differentiation of mesenchymal stem cells into osteoblasts on honeycomb collagen scaffolds, Biotechnol Bioeng, (2006); 95 (3): 404 - 411.

2. Alhadlaq A, Mao JJ. Tissue-engineered neogenesis of human-shaped mandibular condyle from rat mesenchymal stem cells, J Dent Res. (2003); 82 (12): 951 956.

3. Kretlow JD, Mikos AG. Review: mineralization of synthetic polymer scaffolds for bone tissue engineering, Tissue Eng, (2007).; 13 (5): 927 - 938.

4. Pittenger MF, Mackay AM, Beck SC, Jaiswal RK, DouglasR, Mosca JD, Moorman MA, Simonetti DW, Craig S, Marshak DR. Multilineage potential of adult human mesenchymal stem cells. Science, 1999; 284 (5411):143-147.

5. Lee RH, Kim B, Choi I, Kim H, Choi HS, Suh $\mathrm{K}$, Bae YC, Jung JS. Characterization and expression analysis of mesenchymal stem cells from human bone marrow and adipose tissue. Cell Physiol Biochem, 2004; 14 (4-6) : 311-324.

6. Ducy P, Zhang R, Geoffroy V, Ridall AL, Karsenty G. Osf2/Cbfa1: a transcriptional activator of osteoblast differentiation. Cell 1997; 89 (5): 747-754.

7. Zhao Z, Zhao M, Xiao G, Franceschi RT. Gene transfer of the Runx2 transcription factor enhances osteogenic activity of bone marrow stromal cells in vitro and in vivo. Mol Ther. 2005; 12(2): 247-253.

8. Shui C, Spelsberg T, Riggs BL, Khosla S. Changes in Runx2/Cbfa1 expression and activity during osteoblastic differentiation of human bone marrow stromal cells. J Bone Miner Res. 2003; 18 (2): 213221.

9. Paredes R, Arriagada G, Cruzat F, Olate J, van Wijnen A, Lia J, Stein G, Stein J, Montecino M. The Runx2 transcription factor plays a key role in the 1 alpha,25dihydroxy vitamin D3-dependent upregulation of the rat osteocalcin (OC) gene expression in osteoblastic cells. J Steroid 
Biochem Mol Biol. 2004; vol. 89-90, (1-5): 269-271.

10. Ishida K, Yamaguchi, M. Albumin regulates Runx2 and alpha 1 (I) collagen mRNA expression in osteoblastic cells: Comparison with insulin-like growth factor-I. Int J Mol Med. 2005: 16 (4): 689694.

11. Maehata Y, Takamizawa S, Ozawa S, Kato Y, Sato S. Kubota E, Hata RI. Both direct and collagen-mediated signals are required for active vitamin D-3-elicited differentiation of human osteoblastic cells: Roles of osterix, an osteoblastrelated transcription factor. Matrix Biol. 200625 (1): 47-58.

12. Nakashima K, Zhou X, Kunkel G, Zhang Z, Deng JM, Behringer RR, de Crombrugghe $B$. The novel zinc finger-containing transcription factor Osterix is required for osteoblast differentiation and bone formation. Cell 2002: 108 (1): 17-29.

13. Komori T. Regulation of bone development and extracellular matrix protein genes by RUNX2. Cell Tissue Res 2010; 339(1):189- 195.

14. Spinella-Jaegle S, Roman-Roman S, Faucheu C, Dunn FW, Kawai S, Gallea S, Stiot V, Blanchet AM, Courtois B, Baron $R$, Rawadi G. Opposite effects of bone morphogenetic protein-2 and transforming growth factor-beta1 on osteoblast differentiation. Bone. 2001; 29 (4): 323330.

15. Jeong JA, Hong SH, Gang EJ, Ahn C, Hwang $\mathrm{SH}$, Yang $\mathrm{IH}$, Han $\mathrm{H}$, Kim $\mathrm{H}$. Differential gene expression profiling of human umbilical cord blood-derived mesenchymal stem cells by DNA microarray. Stem Cells. 2005; 23 (4): 584- 593.

16. Roobrouck VD, Ulloa-Montoya F, Verfaillie CM .Self-renewal and differentiation capacity of young and aged stem cells. Exp Cell Res. 2008; 314 (9): 19371944.

17. Seo KW, Lee SR, Bhandari DR, Roh KH, Park SB, So AY, Jung JW, Seo MS, Kang SK, Lee YS, Kang KS .OCT4A contributes to the stemness and multi-potency of human umbilical cord blood-derived multipotent stem cells (hUCB-MSCs).
Biochem Biophys Res Commun. 2009; 384 (1): 120-125.

18. Bhandari DR, Seo KW, Roh KH, Jung JW, Kang SK, Kang KS .REX-1 expression and P38 MAPK activation status can determine proliferation/differentiation fates in human mesenchymal stem cells. PLoS One 5 2010: 5 (5): e10493.

19. Watt SM, Contreras M. Stem cell medicine: umbilical cord blood and its stem cell potential. Semin Fetal Neonatal Med. 2005; 10 (3): 209-220.

20. Mcguckin CP, Forraz N. Potential for access to embryonic-like cells from human umbilical cord blood. Cell. Prolif. 2008; 41 (1): 31-40.

21. Erices A, Conget $P$, Minguell JJ Mesenchymal progenitor cells in human umbilical cord blood. $\mathrm{Br} J$ Haematol 2000; 109 (1): 235-242.

22. EL-Serafi AT, Wilson DI, Roach HI, Oreffo RO. Developmental plasticity of human foetal femur-derived cells in pellet culture: self-assembly of an osteoid shell around a cartilaginous core. Eur Cell Mater. 2011; 21:558 567.

23. Musina R, Bekchanova ES, Belyavskii AV, Grinenko TS, Sukhikh GT. Umbilical Cord Blood Mesenchyal Stem Cells. Bull Exp Biol Med 2007; 143(1): 127-131.

24. Livaka KJ, Schmittgen TD. Analysis of relative gene expression data using real time quantitative $\mathrm{PCR}$ and the 2 (delta delta $c(t))$ method. Methods 2001; 25 (4): 402-408.

25. Flynn A, Barry F, O'Brien T. UC bloodderived mesenchymal stromal cells: an overview. Cytotherapy. 2007; 9 (8): 717726.

26. Secco M, Zucconi E, Vieira NM, Fogaça LL, Cerqueira A, Carvalho MD, Jazedje T, Okamoto OK, Muotri AR, Zatz M. Multipotent stem cells from umbilical cord: cord is richer than blood! Stem Cells. 2008; 26 (1): 146-150.

27. Rebelatto CK, Aguiar AM, Moretão MP, Senegaglia AC, Hansen $P$, Barchiki F, Oliveira J, Martins J, Kuligovski C, Mansur F, Christofis A, Amaral VF, Brofman PS, Goldenberg S, Nakao LS, Correa A. Dis 
similar differentiation of mesenchymal stem cells from bone marrow, umbilical cord blood, and adipose tissue. Exp Biol Med (Maywood). 2008; 233(7):901-913.

28. Bieback $\mathrm{K}$, Kern $\mathrm{S}$, Klüter $\mathrm{H}$, Eichler $\mathrm{H}$. Critical Parameters for the Isolation of Mesenchymal Stem Cells from Umbilical Cord Blood. Stem Cells 2004; 22 (4): 625634.

29. Kern S, Eichler H, Stoeve J, Kluter H. Bieback K. Comparative analysis of mesenchymal stem cells from bone marrow, umbilical cord blood, or adipose tissue. Stem Cells. 2006; 24 (5), 1294-1301.

30. Shafiea A, Seyedjafari E, Soleimani $M$, Ahmedbeigi N, Dinarvand P, Ghaemi N. A comparison between osteogenic differentiation of human unrestricted somatic stem cells and mesenchymal stem cells from bone marrow and adipose tissue and umbilical cord blood. Biotechnol Lett. 2011; 33(6):1257-1264.

31. Gronthos S, Zannettino AC, Hay SJ, Shi S, Graves SE, Kortesidis A, Simmons PJ. Molecular and cellular characterization of highly purified stromal cells derived from human bone marrow .J cell sci. 2003; 116(9):1827-1835.

32. Peng L, Jia Z, Yin $X$, Zhang $X$, Liu $Y$, Chen $P$, Ma K, and Zhou C. Comparative Analysis of Mesenchymal Stem Cells from Bone Marrow, Cartilage, and Adipose Tissue. Stem Cell Dev. 2008;17 (4): 761774.

33. Maeno T, Moriishi T, Yoshida CA, Komori H, Kanatani N, Izumi S, Takaoka K, Komori T. Early onset of Runx2 expression caused craniosynostosis, ectopic bone formation, and limb defects. Bone. 2011; 49 (4):673-682.

34. Komori T. Regulation of osteoblast differentiation by transcription factors. J Cell Biochem 2006: 99 (5): 1233-1239.

35. Kanczler JM, Oreffo RO. Osteogensis and angiogenesis the potential for engineering bone. Eur Cell Mater .2008;15:100-114. 
